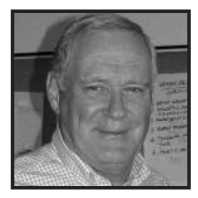

\title{
What Can Sport Expertise Teach Us About Educational Leadership?
}

\author{
A. E. Ted Wall, McGill University
}

\section{ABSTRACT}

Interest in the development of leadership expertise in educational settings has significantly increased in the last decade. The heightened expectations and demands placed on educational leaders have resulted in the establishment of a variety of programs to help them cope with the fast pace of change. This paper describes a model of educational leadership expertise based on a cognitive approach to learning that has been used with participants in my graduate courses on educational leadership for over 10 years. The article suggests that this approach contributes to leadership effectiviness.

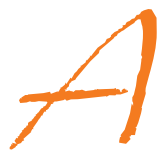

$\mathrm{s}$ the title suggests, the article is based on a comparison between expertise in sport and educational leadership. The five major components of the model presented in Figure 1 will be addressed in turn: namely, key concepts, essential skills, and basic values as well as self-awareness and self-regulation (Wall, 2000). In addition, the comments, observations and suggestions of the participants are integrated into the discussion as an example of how the model has been applied by people interested in the development of educational leadership expertise. The final section addresses several issues related to the development of expertise and the challenge of leading educational institutions in these times of change.

As noted above, a basic premise of this article is that the development of expertise in a variety of fields, including sport and leadership, consists of a complex array of knowledge, skills and attitudes that take time, reflection, and deliberate practice to develop. Over the past twenty years, sport psychologists have spent a 
considerable amount of time trying to understand the development of sport expertise from a cognitive perspective (Ericsson, 1996; Wall, 1986). At the same time, scholars interested in leadership have proposed several frameworks from which to consider the development of leadership expertise (Gardner, Avolio, Luthans, May, \& Walumbwa, 2005; Goleman, 1998; Knuth, \& Banks, 2006). A major assumption of this paper is that a number of similarities exist between expertise in sport and leadership. This paper describes a cognitive model of sport expertise and how it might help us understand and facilitate the development of educational leadership expertise.

The basic model of expertise presented in Figure 1 has proven to be useful in trying to understand both sport expertise and leadership (Wall, 2002). As the figure indicates, the model contends that expertise consists of different types of knowledge that interact in any given situation. The overlapping circles in the figure represent the interactions that take place among the key concepts, essential skills and basic values that an athlete or a leader develops as he or she acquires increasing expertise. As the figure suggests, the basic values of an athlete or a leader provide the foundation for the development of expertise as these values influence the types of ideas that will be used and, in turn, these key concepts determine the skills that will be developed and applied. In my courses on educational leadership, participants are encouraged to consider the specific concepts, skills, and values that they feel are important and to assess the degree to which they are aware of and regulate the development of their own educational leadership knowledge base.

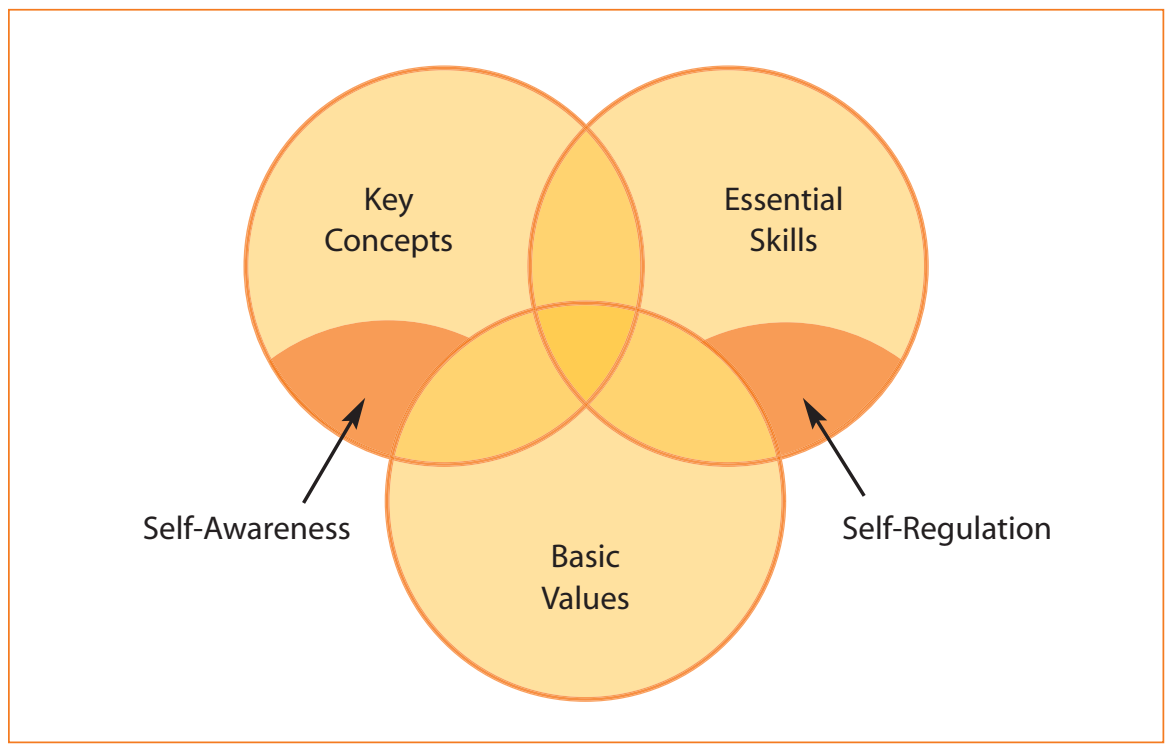

Fig. 1:Types of knowledge underlying expertise in sport and leadership 


\section{Key Concepts}

In order to play a sport effectively, athletes must develop a conceptual knowledge base about various aspects of their sport. Over time, they develop an understanding of the rules of the sport they are playing, the physical constraints imposed by their body while playing it, and an appreciation of the role that their equipment and the environment play in learning and performance situations. Furthermore, they develop a deep understanding of the personal strategies and team tactics that are needed to successfully compete in their sport. Such conceptual knowledge of the game is stored in memory so that it can be accessed quickly at the appropriate time and place. For example, even beginning hockey players must understand the notion of an offside so that when they are passing the puck, they can appreciate the conditions under which the pass must be made in relation to the blueline and the position of their teammates.

In the same way, leaders must understand the conditions under which they are working. Effective leaders develop an understanding of the tasks that must be performed as well as an appreciation of the knowledge, skills, and attitudes of their fellow workers. At the same time, they become aware of the nature of the physical and social environment in which they are working. Expert leaders, like skilled athletes, understand the major tasks facing them within a given situation, the key people in that situation, and the important factors that change, often very quickly, over time (Bass, 1985; Leithwood \& Steinbach, 1995; Yukl, 1989).

There are many important concepts that educational leaders need to understand and apply in their efforts to lead effectively. Three key educational leadership ideas that have recently emerged from the professional literature are: the importance of developing a shared vision, the need to build a distributed leadership system to implement it, and the value of developing a collaborative school culture that supports ongoing professional learning. These key ideas are interrelated and actually reinforce each other.

Over the past fifteen years, qualitative and quantitative research has documented the value of taking a transformational leadership perspective in school settings. Central to that leadership perspective is the importance of setting an appropriate direction and how developing a shared vision can help provide it (Leithwood, 1992; Leithwood, 2006). Just as importantly, if a shared vision is to become a reality, then a distributed leadership system will need to be built within a school to facilitate the implementation of that vision (Lambert, 1998; Stoll, 1998). For example, leader- 
ship within a school can come from a variety of sources including teachers, support staff, students and parents. The contributions that result from such a distributed leadership system are greatly enhanced when the general direction of the school has been shaped by the formal leaders, such as the principal and vice-principals, in collaboration with the teaching staff. The recognition of the critical role played by teachers in such a distributed leadership system has led to an increased emphasis on the importance of understanding the roles and responsibilities that teacher leaders can assume and the skills they need to acquire to effectively contribute to a distributed leadership system (Stoll, Bolam, \& Collarbone 2002; Harris, 2004). Given the pace of educational change, much greater importance has been given to the value of facilitating ongoing professional learning. Effective educational leaders are concerned with developing a positive school culture that encourages the sharing of craft knowledge and values collegial reflection on professional practice. Hence, facilitating school-based teacher learning has become a high priority in many school settings (Harris, 2004; Donaldson, 2007; Leithwood, \& Jantzi, 1999).

It is interesting to note that when participants in my educational leadership courses are asked to identify the top seven leadership practices that they believe should be used in educational settings, developing a shared vision, building a distributed leadership system to support it, and developing a collaborative culture of learning are the ideas that often emerge from the group knowledge-building process. There is little doubt that the assigned course readings affect the above responses; nevertheless, it is near the end of the course that this exercise is completed and the participants are encouraged to choose the leadership practices that they feel are the most important to employ. The three key ideas are invariably included on the list.

\section{Essential Skills}

In this section I consider the role that essential skills play in a familiar sport such as ice hockey. In order to play the game proficiently, in addition to the conceptual knowledge they must acquire, hockey players have to develop skating, stickhandling, shooting, and passing skills. The circle labeled essential skills in Figure 1 refers to this repertoire of physical skills. Elite hockey players develop their skills so that they can be used relatively automatically in fast paced game situations, that is, their skills are so well internalized that when they need them the skills can be performed by the athlete without thinking about how to execute them. 
A basic premise of the model of leadership expertise is that like hockey players, leaders need to develop a set of personal, interpersonal, and group process skills that they can use relatively automatically in a variety of leadership situations. These essential leadership skills will vary depending on the tasks that must be performed and on the organizational structure of the leadership situation (Conger, 1994; Schein \& Bennis, 1965). Three skills of special importance for effective educational leadership are: listening for understanding, building effective teams and planning and monitoring the progress of change.

Listening is a basic communication skill; however, personal experience and the professional literature show that it is not an easy skill to master. Effective listening can enhance interpersonal communication and facilitate the building of trusting relationships; however, it takes time and deliberate practice to acquire this important leadership skill (Ross, 1994). Given the importance of developing a shared vision, building a distributed leadership system and encouraging a culture of ongoing professional learning, understanding the nature of teams and how to build them have taken on even greater importance than they did in the past. Practical suggestions for developing such team-building skills have been widely shared in the leadership literature (Katzenbach \& Smith, 1993; Druskat \& Wolff, 2001). Finally, it is especially important that educational leaders develop skills that are related to group decision-making processes. Being able to facilitate input from colleagues and help move a group toward consensus have proven to be particularly important in facilitating the educational change process (Schein, 1997; Stoll, Bolam, \& Collarbone, 2002).

Again, experience with new and experienced educational leaders has shown me that these three leadership skills are very important and relevant to those who are leading or hope to lead educational institutions. Very often, experienced leaders in the courses or workshops I have taught, find that they need to enhance their listening skills. After completing a short questionnaire on effective listening behaviors, a significant number of the participants realize that they could, as I have, benefit from trying to learn to listen for understanding in a more effective manner. In post-course discussions, many of them have reported that they have improved this important leadership skill and reaped the benefits of doing so.

The importance of knowing how to build and maintain effective teams has also been recognized by those involved in my educational leadership courses. The participants usually agree with the key points that are made about team building in the research literature, and then, based on their own experience, are able to make many useful suggestions to enhance the team-building process. 
The leadership skill that participants recognize as being of prime importance in these times of fast-paced educational change is collaborative group decision making. After discussing the pros and cons of using different types of group decisionmaking approaches, participants report that their increased awareness of when to use these has been especially helpful in their work settings. For example, many of them indicate the value of understanding and applying consensus-building processes, especially when teacher ownership and follow-through are important factors in the implementation of a decision.

\section{Basic Values}

As noted earlier, the location of the third major circle in Figure 1 underscores the fundamental importance that basic values play in the development of expertise in sport and leadership situations. In sport situations, good sportsmanship, fair play, and respecting one's opponent are values that are shared by the vast majority of athletes. As we know, when these values are not followed officials and fellow players impose a variety of sanctions to indicate to the offending athlete that these values must be respected.

Basic values are also very important in leadership situations. For example, trust is one of the most important factors. The development of trust depends on honesty, integrity, openness and a willingness to respect others. Thus, adhering to an appropriate set of basic values is of crucial importance in developing leadership expertise (Kanungo \& Mendonca, 1996; Ghosh \& Wall,1999). More importantly, in order to develop and maintain the trust of their colleagues, leaders need to act in ways that are congruent with the values that they espouse.

As Canadian philosopher Charles Taylor (1986) has noted, when we are involved in situations in which our deepest values are confronted, we often react quite emotionally. When leaders face situations and decisions that involve personal or professional issues that challenge their own or others basic values, they should expect that their deepest feelings will be affected. Thus, it is not surprising that when ethical issues arise effective leaders handle them with great care because of the emotional reactions that might be elicited. Again, participants in my courses have underscored the importance of adhering to a set of basic values. In fact, when they relate stories of educational leaders who they respect greatly, they often refer to the open, honest and caring way that these leaders deal with their colleagues. Put simply, the 
participants do not just refer to the basic values of these leaders, they highlight that the leaders actually "walked the talk" (Bryk \& Schneider, 2003; Jones \& George, 1998).

\section{Self-Awareness}

As important as key concepts, essential skills and basic values are to expertise in sport and leadership, perhaps the two most important components are selfawareness and self-regulation. These are represented by the two semicircles in the skills and concepts components of Figure 1. Self-awareness in a sport situation refers to an awareness of one's strengths and weaknesses in relation to the task demands in a given environment. In hockey, skillful players are aware of how quickly they can skate and shoot the puck as well as how accurately they can pass. Their metacognitive knowledge or self-awareness of their knowledge base is very important as it allows them to select the exact skill that they require at a given time. Moreover, it prevents them from choosing a skill or set of skills that they cannot effectively execute and which, if they tried to use, would only lead to poor execution and an advantage for their opponents. In the same way, their self-awareness allows them to reflect on how well they understand a given situation based on their knowledge of other situations.

Expert leaders also develop self-awareness about their leadership expertise. With experience, they become increasingly aware of the skills, knowledge and values that they have developed and they use metacognitive knowledge to match their leadership expertise to the demands of a variety of situations. More importantly, they use self-awareness to help them strategically control the development of their leadership knowledge, skills and attitudes in relation to the changing demands that they face (London \& Smither, 1999). The notion of strategic control leads to the final component of the expertise model, that is, self-regulation.

\section{Self-Regulation}

The term self-regulation refers to higher level procedures that one can use to plan, monitor, and evaluate one's performance and learning in a variety of sport or leadership situations (Glaser, 1996; Leithwood \& Steinbach, 1995; Wall, 1986). Returning to sport situations and why elite athletes are so successful, it can be argued 
that the most important reason is that they have developed an extensive set of metacognitive skills that have allowed them to strategically plan and control their own learning and performance. For example, in a personal interview with Wayne Gretzky, he recounted how from a very early age his father encouraged him to predict where he should pass the puck based not on where a teammate was on the ice but where he would be when the puck arrived. By encouraging his son to plan his actions in this way, Walter Gretzky was helping Wayne develop his prediction skills. In fact, my interviews with other elite athletes have shown that one of the most important factors in the development of their expertise is their ability to control their own learning. In doing so, they are constantly evaluating and monitoring their own performance and using higher level decision-making skills to enhance their learning and ultimately their ability to perform successfully in stressful situations (Wall, 2002).

In the same way, competent leaders take a special interest in the development of their own leadership knowledge base. They take time to reflect on their leadership performance and strategically think about what they have to learn to improve it. In so doing, they use their self-awareness and self-regulation skills to monitor and evaluate the progress that they are making. This allows them to continually improve their leadership performance.

\section{Expertise and the Challenge of Leadership}

When we watch elite athletes perform in highly competitive, tension-filled game situations, we marvel at their ability to scan the situation and, when needed, focus their attention and execute the necessary skills in a calm, almost relaxed, manner. In contrast to their less skilled peers, elite athletes are able to perform at their peak in these stressful competitive situations. In the same way, expert leaders are able to stay calm, think on their feet, and react appropriately to address a problem or move a group forward to the solution of a problem that confronts them, even though the situation may be stressful. What is it about experts, either in sport or leadership, that allows them to perform in such a confident, self assured way?

Research from the sport domain suggests that an essential factor in such performance is the match between the task at hand and the developmental level of the athlete. In other words, if a task is too difficult or too easy for athletes, they are more likely to experience failure or boredom in attempting to meet the demands of the task. For example, if hockey players cannot skate fast enough, accept a pass in full 
flight, or bodycheck an opponent into the boards easily and effectively, then they are more likely to experience failure in competitive game situations. In fact, most of us have had the experience of trying to play a sport with friends who are just a step above us in skill. We quickly learn that to stay in such a situation whether it is hockey, soccer, or tennis, may only lead to frustration and low feelings of self esteem. If we persist our self confidence can diminish rather quickly and we may well want to withdraw from the activity (Bandura, 1997).

In other words, in sport settings there is no quick fix for being able to play with friends or opponents who have acquired more expertise than we have developed. Unless more expertise is acquired, we will only experience more failure and, in time, feel a negation of our existing ability. Whether we try or not, we are unlikely to experience success. Quite simply, our affective knowledge base is developed over time and if it is to be positive, it usually results from mastering a series of "deliciously uncertain" learning and performance opportunities. Deliciously uncertain tasks are those that are just difficult enough to whet our appetites and keep us practicing and playing so that we acquire the knowledge and skills that are so fundamental to expertise in a particular sport.

In the same way, educational leaders, especially new ones, can lose their confidence and have feelings of anxiety and frustration if they are placed in situations that are so complex that they are unable to lead in an effective manner. For example, a lack of understanding of the basic assumptions inherent within a school culture can place a leader in a very difficult situation. Again, unless the leader takes the time to develop the conceptual knowledge and skills required in more demanding educational leadership situations, he or she may well experience failure and the negative feelings that can lead to a desire to leave the situation. Unfortunately, very often novice leaders are unable to judge how well their developmental knowledge base can handle the demands of leadership in progressively more complex situations (Csikszentmihalyi, 1990; Goleman, 2006). In these moments, the help of more experienced colleagues or mentors may well be able to provide the personal and professional support that is required. Thus, developing a network of experienced colleagues can be especially beneficial for new leaders as they face increasingly challenging educational leadership situations. 


\section{Conclusion}

This article briefly describes a framework of leadership expertise. One of the benefits of developing a model of educational leadership expertise based, on this, or some other appropriate framework, is that it can help one to reflect on the concepts, skills, and values that one is using. By taking the time to reflect on the link between one's knowledge base and performance as a leader, insights about what one knows and does not become more evident. Then, the means can be considered for developing new knowledge, skills and values to enhance one's ongoing effectiveness as a leader. Many of the participants in my educational leadership courses have used the model above, or variations of it, and they report that it was helpful in their development of effective leadership.

\section{References}

Bandura, A. (1997). Self-efficacy: The exercise of control. New York: W. H. Freeman.

Bass, B. M. (1985). Leadership and performance beyond expectation. New York: Free Press.

Bryk, A. \& Schneider, B. (2003). Trust in schools: A core resource for school reform, Educational Leadership, March, 40-44.

Conger, J. A. (1994). Learning to lead - The art of transforming managers into leaders. San Francisco: Jossey-Bass.

Csikszentmihalyi, M. (1990). Flow: the psychology of optimal experience. New York: Harper and Row.

Donaldson, G. A. (2001). Cultivating leadership in schools. New York: Teachers College Press.

Donaldson, G. A. (2007). What do teachers bring to leadership? Educational Leadership, 26-29.

Druskat, V. U. \& Wolff, S. B. (2001). Building the emotional intelligence of groups. Harvard Business Review, March, 81-90.

Ericsson, A. (1996). The road to excellence: the acquisition of expert performance in the arts and sciences, sport, and games. Mahwah, New Jersey: Lawrence Erlbaum Associates.
Gardner, W. L., Avolio, B. J., Luthans, F., May, D. R., \& F. Walumbwa (2005). "Can you see the real me?" A self-based model of authentic leader and follower development, The Leadership Quarterly, 16, 343-368.

Ghosh, R. \& A. E. Wall (1999). Reflections on ethical issues in school leadership, Proceedings of a Symposium on Ethical Leadership in Organizations, Faculty of Management, McGill University, 1-17.

Glaser, R. (1996). Changing the agency for learning: acquiring expert performance. In K. A. Ericsson (Ed.), The road to excellence: the acquisition of expert performance in the arts and sciences, sport, and games. Mahwah, New Jersey: Lawrence Erlbaum Associates.

Goleman, D. (1998). What makes a leader? Harvard Business Review, NovemberDecember, 93-102.

Goleman, D. (2006). The socially intelligent leader, Educational Leadership, September, 76-81.

Harris, A. (2004). Distributed leadership and school improvement. Educational Management Administration and Leadership. 32(1), 11-24 
Jones, G. \& J. George (1998). The experience and evolution of trust: Implications for cooperation and teamwork, The Academy of Management Review. 23(3), 531-546.

Kanungo, R. N. \& Mendonca, M. (1996). Ethical dimensions of leadership. London: Sage Publications.

Katzenbach, J. R. \& Smith, D. K. (1993). The wisdom of teams. New York: Harper Business.

Knuth, R. K. \& P. A. Banks (2006). The essential leadership model. NASSP Bulletin, 90(1), 4-18.

Lambert, L. (1998). How to build leadership capacity. Educational Leadership, April, 17-19.

Leithwood, K.A. (1992). The move toward transformational leadership, Educational Leadership, February, 8-12.

Leithwood, K. (2006). Leadership according to the evidence, Leadership and Policy in Schools, 5, 177-202.

Leithwood, K. \& Steinbach, R. (1995). Expert problem solving: Evidence from school and district leaders. Albany: State University of New York Press.

Leithwood, K. \& Jantzi, D. (1999). The relative effects of principal and teacher sources of leadership on student engagement within school, Educational Administration Quarterly, 35, Supplemental December, 679-706.

London, M. \& Smither, J. W. (1999). Empowered self-development and continuous learning, Human Resources Management, 38(1), 3-15.

Ross, R. (1994). How to listen in skillful discussion, In Senge, P., Roberts, C., Ross, R., Smith, B. J., \& A. Kleiner (Eds.). The fifth discipline fieldbook: Strategies and tools for building a learning organization, New York: Doubleday, 111.
Schein, E. H. (1997). Organizational culture and leadership. $2^{\text {nd }}$ Edition, San Francisco, Jossey-Bass.

Schein, E. H. \& Bennis, W. G. (1965). Personal and organizational change through group methods: The laboratory approach. New York:Wiley.

Stoll, L. (1998). Supporting school improvement. Education Canada. Summer, 14-21.

Stoll, L., Bolam, R., \& Collarbone, P. (2002). Leading for change: Building capacity for learning. In K. Leithwood and P. Hallinger (Eds.), Second International Handbook of Educational Leadership and Administration. Dordrecht: Kluwer Academic Publishers, 41-73.

Taylor, C. (1986). Human agency and language. New York: Cambridge.

Wall, A. E. (1986). A Knowledge-Based Approach to Motor Skill Acquisition, In Motor Development: Aspects of Coordination and Control, M. G. Wade and H.T.A. Whiting (Eds.), Dordrecht, M. Nishoff Publishers, 33-49.

Wall, A. E. (2000). What can sport expertise teach us about leadership? Technical Paper, McGill University.

Wall, A. E. (2002). Understanding sport expertise, Course Textbook, McGill University.

Yukl, G. A. (1989). Managerial leadership: a review of theory and research. Journal of Management, 15, 251-290. 


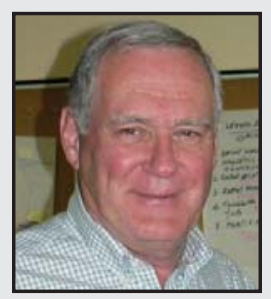

A. E. Ted Wall is a retired Professor and Chairperson of the departments of Physical Education at the University of Alberta and, his alma mater, McGill University. He also served as the Dean of the Faculty of Education, McGill University. Dr.Wall has presented papers and conducted workshops on leadership development in Indonesia, Singapore, South Africa and Trinidad and Tobago. He teaches graduate courses at Bishop's University and McGill University on the development of leadership expertise as well as the educational change process. 